\title{
THE INFLUENCE OF THE COVID 19 ON THE BET AND WIG20 INDICES. COMPARATIVE ASPECTS
}

\author{
Cătălin Florin Bărnuț \\ Doctoral School of Economic Sciences, Faculty of Economic Sciences, University of \\ Oradea, Romania \\ barnutcata@yahoo.com
}

\begin{abstract}
The aim of the paper is to assess the effects of the coronavirus pandemic (COVID - 19) on two stock market indices: BET index for Bucharest Stock Exchange and WIG20 index for Warsaw Stock Exchange. The negative effects of the pandemic have had an influence on the performance of the stock markets since its debut. Many companies as well as sectors have ceased their activity during the outbreak, causing devastating financial losses worldwide. By comparing indices evolution during 2020 using the data available on the stock markets' websites, as well as analyzing in part the companies that make up the indices portfolio, we will try to present the sectors most affected by the pandemic as well as their evolution during the analysis period. The results of this research can be a starting point for future empirical analysis on the long-term effects of the pandemic on stock markets' performance for Romania and Poland. The results could be a source of information for state institutions, companies, investors, analysts but also representatives of the medical sector (responsible for crisis management) - in order to observe the severity and magnitude of the negative effects of the coronavirus pandemic on the financial markets and also help develop and ensue their long-term sustainable growth.
\end{abstract}

Keywords: COVID 19, Bucharest Stock Exchange, Warsaw Stock Exchange, financial market, WIG20, BET.

JEL classification: D53; I15.

\section{Introduction}

The uncertainty and insecurity caused by the global spread of the coronavirus has had an immeasurable impact upon financial markets, affecting all sectors of the economy. A notable problem raised in March 2020 was the "war" between Russia and Saudi Arabia on oil prices, the two states failing to reach an agreement with OPEC+ (Organization of the Petroleum Exporting Countries) - a situation that led to the collapse of oil prices, furthermore, the decrease of the stock markets. (Jacobs, 2020).

The OECD (Organization for Economic Co-operation and Development) has highlighted the fact that companies in many countries have become indebted in recent years, due to the low cost of borrowing. Another factor is the monetary policy which has led to a large corporate debt in many states. The OECD has concluded that businesses will suffer because they have few financial support options, resorting to the reduction of operating costs and redundant of staff in order to cope with the risk of insolvency.

Cite as:

Barnut, C.F., 2021. The Influence of the Covid 19 on the BET and WIG20 Indices. Comparative Aspects. Oradea Journal of Business and Economics, 6(1), pp. 87-95. http://doi.org/10.47535/19910jbe124. 
The leader of the Austrian financial market authority, $\mathrm{H}$. Ettl, stated at the beginning of the pandemic in the European space that "there is no empirical data that can help to assess the future negative effects of the crisis on the economic sector because such a situation has not existed in the past". He also believes that companies with a difficult financial situation before the crisis will now become more unstable.

With the outbreak of the crisis outside China, major global stock indices (NASDAQ-100, Dow Jones, etc.) have seen the steepest declines since 2008 to date. By analogy to the "black Monday of 2008", we can also consider February 27 as a "black Thursday" being marked by the largest decline stocks and indexes (notable is the decline of the Dow Jones index with more than 2.000 points).

Stock markets worldwide declined by over $30 \%$, being described as volatile and risky for investors.

\section{Literature review}

The current economic and social context marked by the epidemiological crisis is unprecedented for the current generation. At an economic level, operators had to respect strict regulations regarding their activity. This imposed the reorganization of strategies and modification of work environment within the company, the sole purpose being the protection of both employees and clients. Managers had all these tasks, being forced to shift their focus towards the protection of the community. Reality showed that those who responded promptly to changes in the economic and social environment, had a more positive evolution on the market. "The quality of governance is influenced by several factors, at both microeconomic and macroeconomic level. Economic crises have a direct link between governance and economic growth, which leads to the need for long-term strategies to have good governance." (Noja et. al., 2019)

Although globalization has an important role to play in creating links between the world's economies, it has also led to an increase in interdependence between financial markets in recent decades. Despite its benefits, globalization plays a crucial role in the context of a pandemic. The International Monetary Fund (IMF) said that the COVID-19 pandemic generated an unprecedented crisis, being characterized by the following: it is versatile (because it affects the links between the economy and the health system), it is uncertain (because at its beginning there was no real treatment and the measures taken regarding isolation were chaotic) and it has a global character. Pak and Adegboye (2020) drew the following conclusions: supply decreases due to the closure of companies and decreased productivity, while demand decreases due to deliberately low consumption among the population.

The WHO (World Health Organization) supported by health representatives, acted as intermediaries in shaping investors' perceptions of the pandemic as well as their understanding of current financial risks. (Smith, 2006:. 3113-3123)

When there is an upward trend and a low risk on the financial market, investors are optimistic, but when the market registers a downward trend and presents a high risk, investors become more cautious, waiting for the market to recover. (Lu, \& Lai, 2012:621-629)

Other studies have concluded that the media also has a significant effect upon financial markets because a high number of articles regarding an unexpected situation leads to increased panic among investors. (Engelberg \&Parsons, 2011: 67-97). In the case of the coronavirus pandemic, the media was oriented only towards the gravity of the situation feeding the fears of the population. Also, on this topic, Cepoi (2020) investigated the correlation between COVID-19 related news and stock market returns across the top six most affected countries by the pandemic (USA, UK, Germany, France, Spain and Italy). The 
results showed that stock markets developed an asymmetric dependency with information related to COVID-19, thus making it necessary to use appropriate communication channels, to attenuate the volatilities generated by the pandemic on financial markets.

Contessi and De Pace (2020) presented statistical evidence of instability using 18 market indices during November 1, 2019 to May 31, 2020, materialized in the collapse of the stock markets at the beginning of March.

An important conclusion was formulated by Ramelli and Wagner (2020) who studied the cross-section of stock price reaction to COVID-19 concluding that the most affected were the companies with low cash and a high degree of indebtedness.

\section{Data and methodology}

The current, unprecedented context caused by the pandemic offers us the opportunity to assess the impact it has on stock markets. In this study we will describe the negative effects of the pandemic across two stock markets - Bucharest Stock Exchange and Warsaw Stock Exchange. By analyzing the evolution of the two main indices of the markets - BET index for BSE (which includes the 17 most traded companies) and WIG20 index for WSE (which includes shares of 20 major and most liquid companies in the Main List) we will describe the evolution of the companies that make up the indices portfolio in order to asses the magnitude of the effects and to show the most affected sectors by taking into account the stock price evolution. The data regarding the markets will be collected from the stocks' websites.

\section{Indices presentation and evolution}

After the first cases were registered in both countries and with the rapid growth in the following weeks, country officials showed great interest towards the financial sector by ensuring continuous access to liquidity, extending reports deadlines and also tax payment deadlines, enabling focus on customer service, providing necessary medical materials and services in order to fight against the ongoing pandemic.

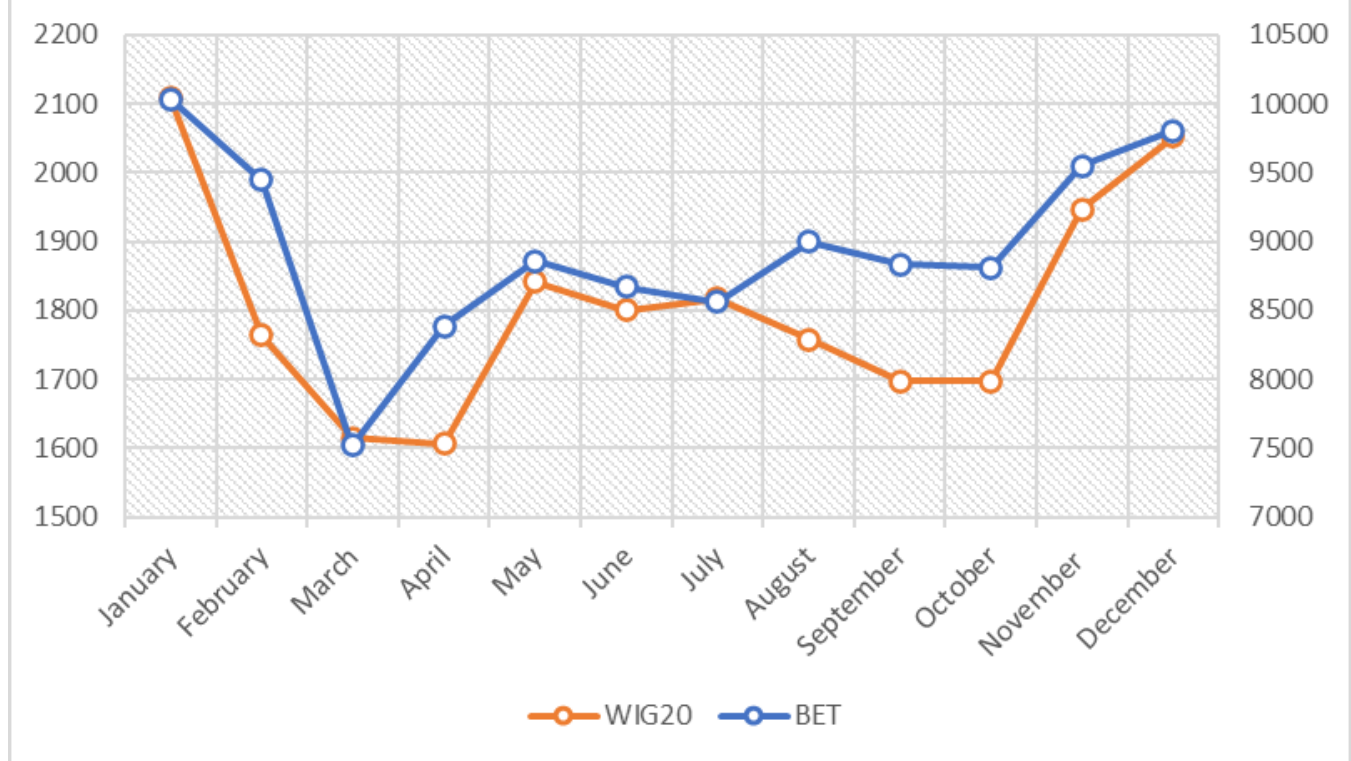

Figure 1. BET index and WIG20 index evolution between January and October 2020 (WIG20 left axis, BET right axis) 
Source: Authors' elaboration based on data from ceicdata.com

The Romanian Capital Market started the year 2020 with a growth of the BET index, reaching its' highest value in the last 12 years in January (over 10,000 points). The optimism of the Romanian stock market started to diminish once the pandemic ceased activity in many sectors of the economy.

The Polish stock market started 2020 with a lower value of WIG20 (approximately 5\%). Financial analysts forecasted for 2020 an increase of the main indices as well as the easier obtaining of profit on the small and medium companies' segment. Also, analysts forecasted an $8 \%$ increase of the WIG20 index.

In order to describe the way in which the coronavirus pandemic affected the financial markets in Romania and Poland, the evolution of the indices was compiled and compared for the year 2020 .

According to Figure no. 1, we can see the steep decline registered by both indices starting from mid-March. The BET index took a drop of almost $30 \%$ from $1^{\text {st }}$ of January to $23^{\text {rd }}$ of March, while WIG20 index decreased with almost 40\% during the same period. The current context of COVID-19 has had a direct impact on the evolution of the capital market, presented through the massive depreciation of shares due to investors' fears regarding the pandemic.

\subsection{The evolution of the BET index}

Companies listed on BSE had registered a positive evolution in April, the first full month of voluntary blockage of the economic system due to the establishment of the state of emergency by the Romanian government. The total trading value on all types of financial instruments approached 1 billion euros in April (an increase of 34\%), while the average daily trading value was almost 11 million euros in January- April (up with $30 \%$ ).

Private pension funds have taken full advantage of the revaluations of listed companies, becoming among the most active investors of the Romanian stock market during the health crisis.

At the end of June, the BET index reached the level of 8,659 points (-13.21\%), and Romania ranked ninth in the EU according to the evolution the main indices of the capital markets during the first semester of 2020.

At the end of August, the BET index ranked 19th out of a total of 34 countries analyzed (with a difference of $16 \%$ compared to the beginning of the year). Out of the total of 17 issuers, 9 companies closed the first seven months of 2020 with a profit. Teraplast was the leader with an increase of over $50 \%$ due to the announcement of the sale of business lines, while Nuclearelectrica registered an increase through the generous dividend offered. On the downside, BRD SocGen had the weakest evolution in the index, due to the banking sector being strongly affected by the pandemic. Another company with a significant decrease was Sphera Franchise Group, due to the restaurant industry being severely affected by the current situation. OMV Petrom, the largest oil producer in Central and Eastern Europe, registered the third weakest evolution with a depreciation of $23.71 \%$. This evolution was also influenced by the sharp drop in the price of oil, which traded at historic lows. A report published by BSE specifies that it ended the first eight months of 2020 with listings of over 500 million euros, eight issuers managing to attract financing.

September was marked by a great historical event in the evolution of the Bucharest Stock Exchange. Quoting the CEO of the Romanian Stock Exchange "as of September 21, 2020, there has been a visible effect on BSE in terms of investor activity. The two companies that have met the criteria for inclusion in All-Cap indices dedicated to emerging markets are Banca Transilvania - the most traded company on the stock market - and Nuclearelectrica. Due to the promotion, the Bucharest Stock Exchange expects more foreign capital inflow. 
Despite the positive situation recorded at the end of August, October came with big depreciations (almost 6\% for BET). The banking sector has been hit hard by the deteriorating outlook for economic recovery. BRD SocGen shares fell $12.46 \%$, while Banca Transilvania shares depreciated by $12.09 \%$. After the banking sector, the shares of Purcari Wineries are in the top of the decreases, the titles of the wine producer from the Republic of Moldova registering a decline of $9.91 \%$. The food industry, to which the company's activity is strongly linked, is being affected by the measures imposed by the authorities to limit the spread of the virus. Shares of Sphera Franchise Group, the other issuer in the index whose operations are dependent on the same industry, depreciated by $7.69 \%$ in October, hitting a record low.

In addition to those mentioned, energy producing companies had registered decreases overall at the end of October; Romgaz shares a depreciated with $5.16 \%$ (recording the lowest price since January 2017 - with a decrease of $23.8 \%$ of natural gas production in the 3rd quarter of the year 2020 compared to the previous year). Nuclearelectrica shares fell $5.15 \%$ and OMV Petrom shares fell 5.01\%. On the other hand, except for Conpet, the utility companies (Transelectrica, Electrica and Transgaz) from the BET index had registered an increase.

The BET index ended 2020 with a value of 9,805 points, a decrease of $1.72 \%$ compared to its value at the beginning of the year (9,997 points). The capitalization of the main segment, compared to the value for 2019 , was lower by $14.64 \%$. On the other hand, the total value of transactions increased by $55.79 \%$ compared to the previous year, a particularly important aspect (almost 3 million Euros).

\subsection{The evolution of the WIG20 index}

In the case of the WIG20 index, the evolution was similar to that of the BET index.

In the half-yearly report published on the stock exchange's website, the CEO of WSE noted that: "the dynamic recovery of indices led to the record-high turnover that continued into Q2. The sharp fall of stock prices followed by a strong recovery brought new investors to the capital market. Brokers opened more than 70 thousand new accounts for clients in $\mathrm{H} 12020$. We expect that most of those new investors will stay on the capital market for good. The coronavirus pandemic triggered high volatility of stocks and other financial instruments traded on exchanges all around the world including Poland. The value of turnover in shares on the GPW Main Market was record-high at more than PLN 131 billion in H1 2020 and investor activity peaked in June." (Szaniewski and Dudkowska, 2020)

The WIG20 index ended August with a value of approximately 1,800 points. Analysts suggested that the index was one of the weakest indices in Europe. Its decline might be related to the reduction of about $2.5 \%$ in $\mathrm{MSCI} E M$, which is an indirect benchmark for it. The performance of the WSE was clearly affected by the energy sector, due to the lack of investors in London - the las session of August being marked by a decrease in turnover overall.

At the end of September, WIG20 closed with a value of approximately 1,700 points, depreciating by $4.9 \%$. Out of the index portfolio, the biggest share was primarily held by CD Projekt, which lost over 8.5\% during the month, registering a turnover of PLN 459 million which represents more than half of the turnover for the entire blue-chip index. This shows the weakness of the Polish stock market, where a large company influences the entire market.

Still weak in the WIG20 index, oil companies registered depreciations, both PKN Orlen (decrease of $3.4 \%$ ) and Lotos ended the month in the red, joined by the mining sector (JSW with a depreciation of $2.53 \%$ ). Apart from those mentioned, KGHM (major producer of copper and silver) decreased the most in WIG20 at the end of September $(-2.53 \%)$. On the energy sector, the largest depreciations were recorded by the following companies: PGE 
which decreased the most (-6.1\%) and Tauron - with a decrease of 3.5\%. In the oil and gas sector, the company that stood out with a significant loss was PGNiG, with a decrease of $3.3 \%$.

On the opposite pole, CCC company stood out, publishing good results for Q3 - the company also boasts about customers who return to shopping due to the excellent products acquired. The energy sector registered a positive evolution as well.

After the October 14 session of trading on the WSE, Allegro - a Polish online e-commerce platform - replaced mBank in the WIG20 index. After just a few days after entering the index, Allegro managed to hold the largest share in the portfolio of the WIG20 index, thus, it finally dethroned CD PROJEKT - computer game manufacturer - as the largest company listed on the exchange.

On October 19, Allegro entered the FTSE indices, and from October 26, the company was included in the MSCl indices. With this classification, analysts and investors hoped that this will lead to the faster recovery of the Polish stock market.

Despite the high hopes, the end of October was characterized by a significant decrease of the WIG20 index compared to the previous months (WIG20 fell by around $11.5 \%$, reaching approximately 1.550 points). In terms of trends, as of September 30, 9 companies were on a downward trend, while 10 companies were on an upward trend. The affected sectors are:

- the banking sector (Alior, mBank, Pekao, Santander),

- oil-petroleum (Lotos, PKN-Orlen),

- telecommunications (Orange, Play-Comm.)

- insurance (PZU) - reaching the lowest value in history, at 22.93 PLN.

The banking sector performed particularly poorly, PKO BP shares being traded at historical lows. Analyst responded that "we should only be glad that the banking sector weighs less and less in WIG20, because it would only reduce the performance registered by the index" (Beck, 2020).

Investors have once again become concerned about the quality of bank loan portfolios. The decline in banking companies is reinforced by weaker overall sentiment in the stock markets. Santander registered the lowest values since 2009, at 132 PLN, followed by Orlen, which reached its lowest values in the last 6 years.

Given that market pessimism is primarily due to concerns about the rising number of cases and the possible lockdowns that might take place in many countries around the world, there is little evidence that the situation will change drastically in the near future. In Europe, severe restrictions have been imposed on all major economies. There are also restrictions in almost every other country on our continent, which is very likely to have a negative impact on all economic activities. In Poland, the media is flooding the population with information about a possible complete blockade.

The current situation of the WIG20 is optimistic. After the first wave of growth in early November, the evolution of the index has been relatively stabilized. Currently, the index is heading towards 1,850 points, which is the peak of consolidation in June-August. This is now an important resistance for the WIG20, being saved by Allegro and CD Projekt from stagnation.

WIG20 ended 2020 with a value of 1,984 points, exceeding 2,000 points in 2021. For 2020, the decrease was $8.74 \%$ compared to the value at the beginning of the year. Increases were recorded by CCC and LPP, but the index's yield was declining due to companies in the banking sector that continued to show a downward trend. CD Projekt registered a 30\% drop in share prices in December with the launch of the long-awaited video game Cyberpunk 2077 - a game that was ultimately a big disappointment for many. Orange also ended 2020 with a decrease of $1.44 \%$. 


\section{In conclusion}

Indices of major stock markets in Europe and the United States marked significant depreciation in the recent months, amid rising numbers of coronavirus cases, the presidential elections and talks for a new US economic stimulus package or new restrictions on some European countries to limit the spread of the COVID-19 virus. These factors were also present in the evolution of the analyzed BET and WIG20 indices.

For investors, we can conclude that in the end it is not only the company's business factors that matter but also the existing risks regarding investments in the current epidemiological context. The results of this study show that:

- The COVID-19 outbreak has severely affected stock markets worldwide - the most affected being the banking sector, oil-petroleum, food industry, tourism and so on.

- The pandemic affected companies' activity and had an impact on the employment which will take much longer to recover, destabilizing the market overall (from mid-March, many companies had ceased their activity causing unemployment rates to rise)

As we have seen, almost the entire year of 2020 has been marked by a rapid growth in coronavirus cases worldwide. It is important to find solutions to avoid the current problems in the health sector and the financial sector.

For investors, the economic crisis caused by the pandemic leads to a decrease in economic activities, implicitly they are worried about their future income. Intuitively, some of them resorted to selling shares as the virus spread globally.

The economic recovery requires a policy response in the short, medium, and long term. The short-term goal of support is not to stimulate the economy but rather to avoid mass layoffs and bankruptcies. (Loayza, 2020). The medium-term macroeconomic policy should focus on recovery measures. Central banks could respond by reducing interest rates. However, as the shock is a multi-faced crisis, monetary, fiscal, and health policy responses are expected. The articles' results contribute to the literature regarding the impact of the coronavirus on the economic sector and can also be a source of information for state institutions, companies, investors, analysts but also representatives of the medical sector (responsible for crisis management) - in order to observe the severity and magnitude of the negative effects of the coronavirus pandemic on the financial markets and also help develop and ensue their long-term sustainable growth.

A limit of the research can be the descriptive analysis performed, done by comparing the results obtained by the companies. This offers only a general image of the markets' health and the effects of the pandemic upon them. Future directions of research can be oriented towards an empirical analysis in order to stablish the causal relationship between the effect and the results. Another limitation is that the study was focused on only two financial markets.

\section{References}

Beck, T., 2020. How is coronavirus affecting the banking sector? [online]. Available at:https://www.economicsobservatory.com/how-coronavirus-affecting-banking-sector [accessed 18.01.2021].

Bucharest Stock Exchange website: http://www.bvb.ro/ [accessed 05.01.2021] Cepoi, C.O., 2020. Asymmetric dependence between stock market returns and news during COVID-19 financial turmoil. Finance Research Letters, 36, https://doi.org/10.1016/..frl.2020.101658

Contessi, S., and De Pace, P., 2021. The international spread of COVID-19 stock market collapses. Finance Research Letters, 9, https://doi.org/10.1016/.ffrl.2020.101894 
DerStandard, 2020. FMA-Chef Ettl: "Den Absturz der Wirtschaft aufhalten" [online]. Available at: https://apps.derstandard.at/privacywall/story/2000116461884/fma-chef-ettl-den-absturz-de r-wirtschaft-aufhalten [accessed 18.01.2021].

Engelberg, J.E., Parsons, C.A., 2011. The Causal Impact of Media in Financial Markets. The Journal of Finance, 66 (1), pp. 67-97, https://doi.org/10.1111/j.1540-6261.2010.01626.x Loayza, N. V.; Pennings, S., 2020. Macroeconomic Policy in the Time of COVID-19: A Primer for Developing Countries. Research and Policy Briefs, no. 28;. World Bank, Washington, DC. https://openknowledge.worldbank.org/handle/10986/33540

Lu, X.-F \& Lai, Kin Keung \& Yu, Lean, 2010. Relationship between stock indices and investors' sentiment index in Chinese financial market. Xitong Gongcheng Lilun yu Shijian/System Engineering Theory and Practice, 32

Necula, I., 2020. Romania ranked ninth in EU in terms of developments in main capital market indices [online]. Available at: https://www.stiripesurse.ro/romania-ranked-ninth-in-eu-in-terms-of-developments-in-main-c apital-market-indices 1486529.html [accessed at 07.01.2021]

Noja, G.G.; Cristea, M.; Sirghi, N.; Hategan, C.-D.; D’Anselmi, P., 2019. Promoting Good Public Governance and Environmental Support for Sustainable Economic Development. International Journal of Environmental Research and Public Health, 16 (24), 4940. https://doi.org/10.3390/ijerph16244940

OECD, 2020. Global financial markets policy responses to COVID-19 - OECD Policy Responses to Coronavirus (COVID-19), OECD Publishing, Paris, https://doi.org/10.1787/2d98c7e0-en.

Pak A., Adegboye Oyelola A., Adekunle A. I., Rahman Kazi M., McBryde E.S., Eisen Damon P., 2020. Economic Consequences of the COVID-19 Outbreak: the Need for Epidemic Preparedness. Frontiers in Public Health, 8:241. http://doi.org/10.3389/fpubh.2020.00241

Ramelli, S., Wagner, A.F., 2020. Feverish Stock Price Reactions to COVID-19. The Review of Corporate Finance Studies, 9 (3), pp. 622-655 https://doi.org/10.1093/rcfs/cfaa012

Smith, R. D., 2006. Responding to global infectious disease outbreaks: Lessons from SARS on the role of risk perception, communication and management. Social Science \& Medicine, 63 (12), pp. 3113-3123. https://doi.org/10.1016/i.socscimed.2006.08.004

Szaniewski, D., and Dudkowska, A., 2020. The rate of return and the investment risk in the shares of the IT industry companies quoted on the GPW Stock Exchange Basic Market. Military Logistics Systems, 52 (1), pp. 159-170. https://doi.org/10.37055/s/w/129251

Trent, J., 2020. OPEC+ Moves To End Price War With 9.7 Million B/D Cut. Journal of Petroleum Technology, 72 (05), pp. 38-40. doi: https://doi.org/10.2118/0520-0038-JPT

Warsaw Stock Exchange website: http://www.gpw.pl/ [accessed 05.01.2021].

Yun Li, 2020. Dow sinks 2,000 points in worst day since 2008, S\&P 500 drops more than $7 \%$ [online] Available

at: https://www.cnbc.com/2020/03/08/dow-futures-drop-700-points-as-all-out-oil-price-war-add s-to-coronavirus-stress.html [accessed 18.01.2021].

\section{Bio-note}

Cătălin Florin Bărnuț is a PhD student at the Doctoral School of Economic Sciences, Faculty of Economic Sciences, University of Oradea, Romania. In his doctoral research he focuses on stock markets performance, mainly companies listed on the Bucharest Stock Exchange and Warsaw Stock Exchange. 